\title{
Development of Foot Step Power Generation using Piezo Electric Sensors
}

\author{
K. Varalaxmy Nithya, V.Iswariya, K.Harini, K.Hemalatha
}

\begin{abstract}
This project was developed to need for a system that generates non conventional energy. Energy crisis is one of the major issues worldwide. This paper proposes maximum utilization of human locomotion energy for power generation using Piezo electric sensors. The basic principle was, any vibration or pressure that generate between surface and footsteps while walking, is converted into electric energy using Piezo electric transducers. A series connection of Piezo electric transducers are mounted on the tile and this tile is placed in the crowded area for the generation of electric energy. This paper explores the power generated by footsteps and used for mobile charging.
\end{abstract}

Keywords: Footstep Power generation, Piezo electric Sensors, Transducer, Voltage regulator, Rechargeable battery.

\section{INTRODUCTION}

Human activity is over loading our atmosphere with Carbon dioxide and other global warming emissions which causes harmful effects. Energy demand also increasing now-a-days and there is a need for inventing alternative source of energy to cater the needs of human requirements. This paper explores a positive impact that is generating electricity from the waste energy. According to a health line survey an average human foot step is 3000 to 4000 per day. When a person walked on road surface, there is a loss of energy in the form of impact, vibration etc. transfer from his weight. This vibrating energy is trapped in an efficient manner and converted into usable energy. This paper explores about the generation of electric energy that can extract from the vibration by Piezo electric sensors placed on tiles, which are placed in crowed area. The Piezo electric sensors are mounted in series connection in order to extract maximum energy. When any pressure, vibration etc is applied to the Piezo electric material it will convert mechanical energy into electric energy by deforming its crystal lattice. The voltage generated across Piezo electric tile is furnished to a battery through voltage regulator to get constant voltage. This voltage can be used for Street lights, charging of mobiles in public places like metro stations, public squares etc. This paper describes basic concepts, Design details and development of working model of power generation through footsteps using Piezo electric sensors.

Manuscript received on August 18, 2021.

Revised Manuscript received on September 24, 2021.

Manuscript published on September 30, 2021.

* Correspondence Author

K.Varalaxmy Nithya*, BE, ECE Department, R.M.K College of Engineering \& Technology, Chennai, India. Email: kavu18ec057@rmkcet.ac.in

V.Iswariya, BE, ECE Department, R.M.K College of Engineering \& Technology, Chennai, India. Email: iswa18ec042@rmkcet.ac.in Technology, Chennai, India. Email: hari18ec037@rmkcet.ac.in

K.Hemalatha, BE, ECE Department, R.M.K College of Engineering \& Technology, Chennai, India. Email: hema18ec039@rmkcet.ec.in
K.Harini, BE, ECE Department, R.M.K College of Engineering \&

\section{PIEZOELECTRIC PRINCIPLE}

\section{A. Piezoelectric effect}

Piezoelectric effect is the ability of certain materials that can generate AC voltage when subjected to mechanical stress or vibration.

\section{B. Working Principle}

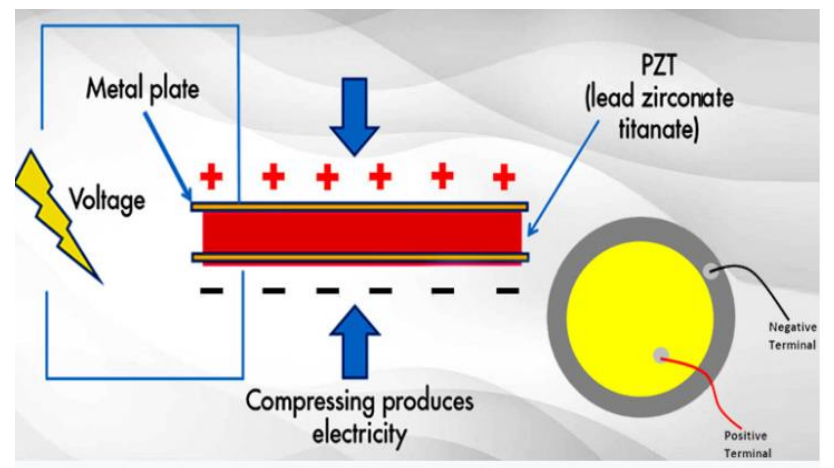

Fig.1 electric effect

Piezoelectric effect is shown by materials like Quartz $\left(\mathrm{SiO}_{2}\right)$, Berlinite $\left(\mathrm{AlPO}_{4}\right)$, Gallium Orthophosphate $\left(\mathrm{GaPO}_{4}\right)$, Tourmaline Barium Titanate $\left(\mathrm{BaTiO}_{3}\right)$ and Gallium Orthophosphate $\left(\mathrm{GaPO}_{4}\right)$. When mechanical stress is applied across these materials, the crystalline structure is disturbed and changes the direction of polarization of dipole due to reorientation of molecular groups. As a result electric potential is developed across its terminals. The reverse phenomenon also happens and called Indirect Piezo electric effect.

\section{Piezo electric Transducers}

A Piezo electric Transducer is a device that utilizes Piezo electric effect to measure the changes in pressure, acceleration, strain, temperature and force by converting this energy into electric energy. Piezo electric sensor shown in Fig. 2.

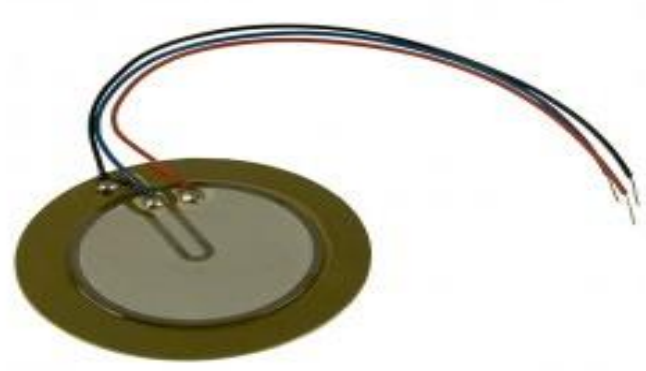

Fig.2 Piezo electric sensor

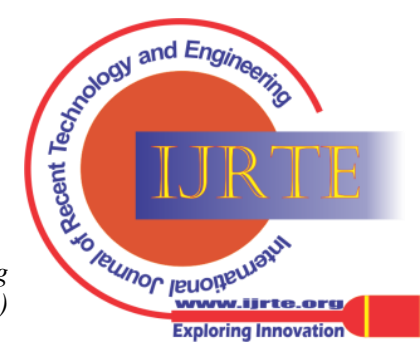




\section{LITERATURE SURVEY}

A detailed study was done on alternate methods for generation of electricity and non conventional energy sources were done. An Elsevier research paper provides details of Hybrid nano generator using tribo electric, Piezo electric with different structures and optimized system based on available space using shoe sole [1]. An article from `Expert skiphire' explains about generation of electricity by up and down movement on sustainable dance floor [2].

A Research gate paper provides the details of Power generation from Piezoelectric Footstep technique using rack implementation of street lights using pedestrian powered electricity [4]. A research study on renewable energy for sustainable development in India by Charles and M.A.Majid. This paper explains current status, future prospects and challenges in the sector [5]. A paper from Strain journal explains estimation of Electric charge output using Piezo electric energy harvesting [6]. Electricity from footsteps, by SS Taliyan, BB Biswas, RK Patil, GP Srivatsav and Basu, This paper discusses the basic Engineering and operating mechanism of Piezo electric crystal, model and generation through footsteps [7]. Yuki Bunda, Kajiro Watnabe, Kazuyuki kobayashi, Yoshike Kurihara, `Measurement of static electricity generated by human walking' IEEE explore, $14^{\text {th }}$ October, 2010[8]. A Research paper on application of piezoelectric transducer in energy harvesting in the pavement by Xiaochen $\mathrm{Xu}$, Dongwei Cao. This paper states that utilization Piezo electric transducers in green energy have has developed the shoes that will generate electricity from the kinetic energy generated by walking. Our team has put a lot of effort on reference books, international journals and articles for development of this project.

\section{METHODOLOGY}

The purpose of this paper is to explore alternative sources for producing electricity by utilising waste energy. As per the survey report of World resource research report, India is responsible for $6.8 \%$ of global carbon emissions. According to a World Energy council prediction, global electricity demand will peak in year 2030. Govt of India aims to produce $175 \mathrm{MW}$ of power only from renewable Energy.

The reason for choosing the Piezo electric transducer in this project is due to its durability and efficiency with reliable operation.

\section{BLOCK DIAGRAM}

Block diagram for the development of foot step generation using Piezo electric sensors is shown in Fig.3. A series arrangement of Piezo electric transducers which are placed on tiles, connected to the diode circuit. This will further connected to rechargeable battery through a regulator circuit. and pinion system [3]. An article from Citylab shows the bright future [9]. Japanese telecommunications giant, NTT,

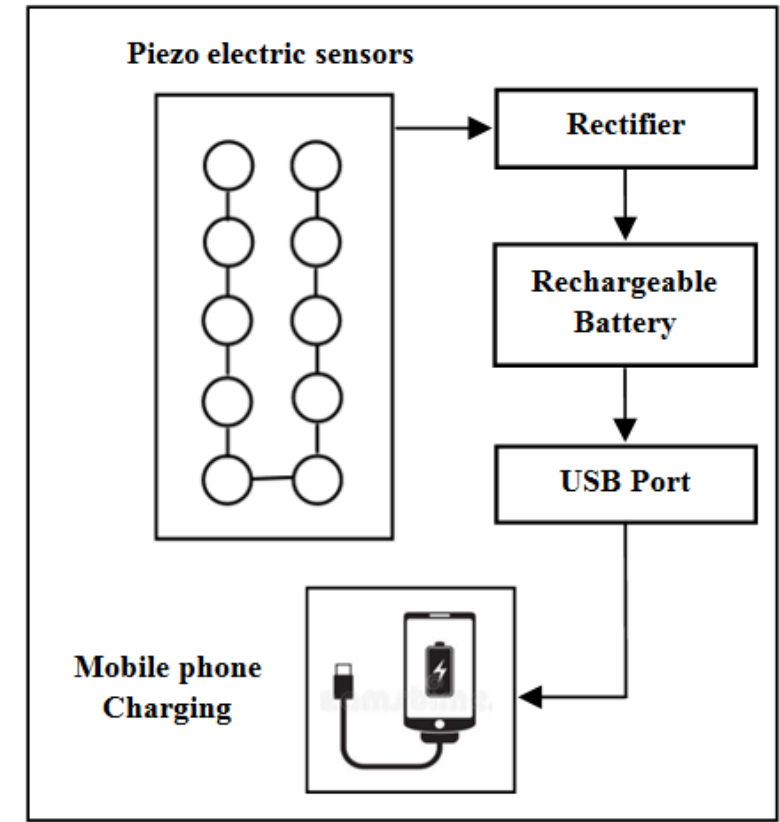

Fig.3 Block diagram of electric generation
using foot steps

\section{CIRCUIT DESIGN}

Piezo electric sensors are arranged in series connection and attached beneath the tile. This will be connected to a regulator of $5 \mathrm{~V}$ to get constant voltage further connected to rechargeable battery. A USB port is connected for mobile charging purpose.

\section{A. Components}

The main components are

$>$ Piezo electric transducer

$>7805$ regulator

$>$ Rechargeable battery

$>$ USB port

\section{B. Circuit Fabrication}

Fabrication and development model of circuit is shown in Fig. 4 below.

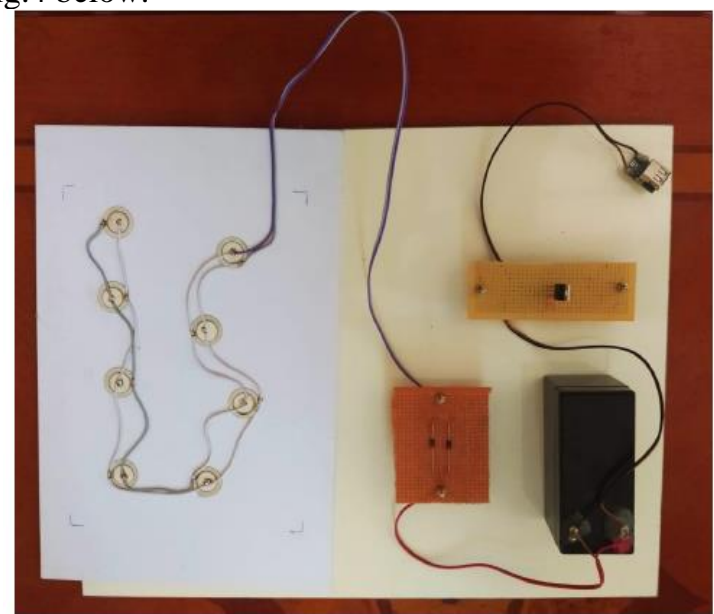

Fig.4 Development model for power generation

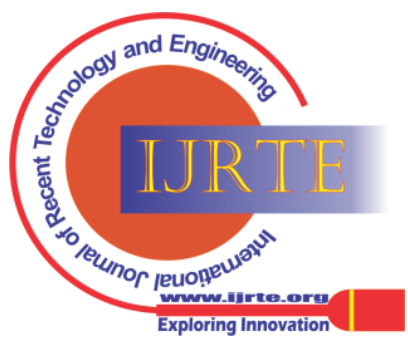




\section{Test setup and Results}

The circuit was tested by applying various levels of pressures of different people having weights in the range $40 \mathrm{Kgs}$ to $80 \mathrm{Kgs}$. The generated voltage is utilized for charging mobile phone as shown in Fig. 5 below.

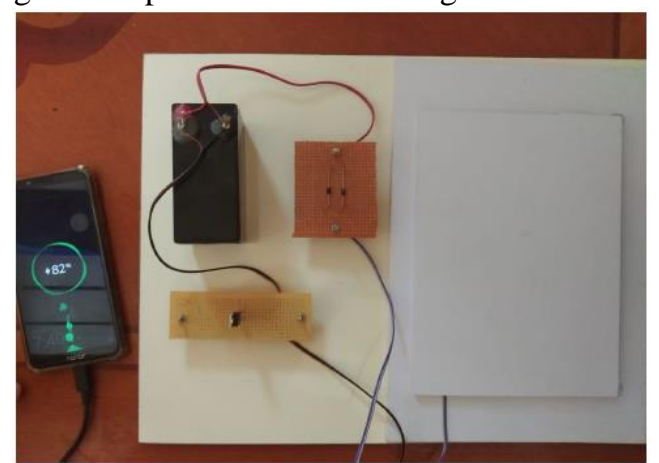

Fig.5 Test set up for Voltage generation

The test results were plotted as weight in Kgs. Vs generating Voltage as shown Fig.6 below.

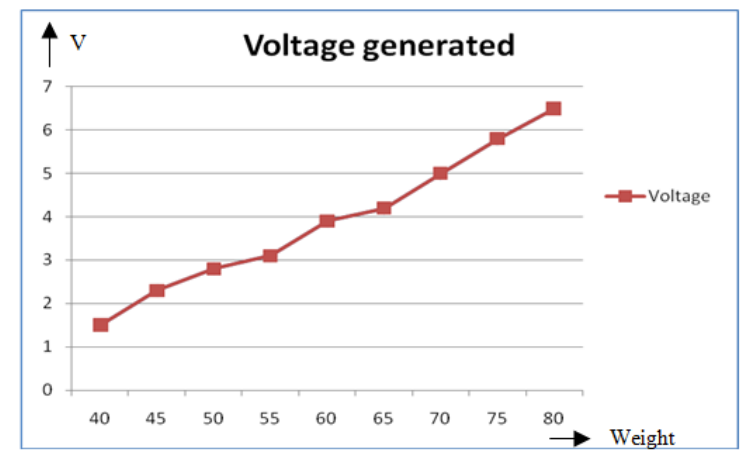

Fig.6 Test results - Voltage generation

\section{CONCLUSION}

After successful testing of working model it was concluded that foot step power generation using Piezo electric sensors is the best solution for alternating energy source for low power application areas with low cost.

\section{ACKNOWLEDGMENT}

We would like to thank our mentor Mrs. Dhivya. K, Asst. Professor, RMKCET, Dr.N. Gangatharan Head Of Dept. RMKCET Chennai, who motivates and support this work.

\section{REFERENCES}

1. Catia Rodrigues, 'Power generating footwear based on a Tribo electric - electromagnetic - Piezo electric hybrid nano generator' Elsevier, Nano Energy : 62(6), DoI:1010.16/j.nanoen.2019.05.063.

2. German Clubbers to generates Electricity on the Dance floor', Written by Expert Skip hire on 18 February 2019.

3. Muhammad Aamir Aman, 'Power Generation from Piezoelectric Footstep Technique' Research gate, December'2018, DOI: 10.272 jmcms.20181000006.

4. LindaPoon, https://www.bloomberg.com /news/articles/2016-04-01/las -vegas-gambles-with-pedestrian-powered-solar-kinetic-streetlights, City lab

5. Charles Rajesh kumar, M.A.Majid `Renewable Energy for sustainable development in India: Current status, future prospects, challenges and Employment \& investment opportunities, BMC article no:2, 2020.

6. Henry A. Sodano, Daniel J. Inman, 'Estimation of Electric Charge Output for Piezoelectric Energy Harvesting', LA-UR-04-2449, Strain Journal, 40(2), 49-58, 2004, Gyuhae Park. Center for Intelligent Material Systems and Structures Virginia Polytechnic Institute and State University.

7. S.S.Taliyan, B.B. Biswas, R.K. Patil and G. P.Srivastava, Electricity generation from Footsteps 2010 Reactor Control Division, Electronics \& Instrumentation Group and T.K. Basu IPR, Gandhinagar.

8. Yuki Bunda, Kajiro Watnabe, Kazuyuki kobayashi, Yoshike Kurihara, 'Measurement of static electricity generated by human walking' IEEE explore, 14thOctober, 2010.

9. Xiaochan $\mathrm{Xu}$, Dongwei Cao, Hailu Yang, Ming He, 'Application of Piezo electric transducer in energy harvesting in pavement' Vol 11 Issue 4, pages 388-395, July 2018.

10. Endgadgett:https://www.engadget.com/2008-10-20-ntts-energy-generat ing-shoes- spotted- without-any-sign-of-stylis.html.

11. Antiono Arnau nd Davis Soares, Fundamentals of Piezo electricity, Springer link Book, pp1-38.

\section{AUTHORS PROFILE}

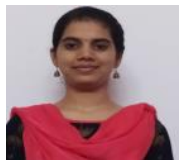

K.Varalaxmy Nithya, persuing BE (ECE) $3^{\text {rd }}$ year in RMK College of Engineering \& Technology, Chennai. She has developed IoT based Research Projects. Her area of interest is Embedded systems and VLSI design.

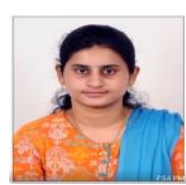

V.Iswariya, persuing BE (ECE ) $3^{\text {rd }}$ year in RMK College of Engineering \& Technology, Chennai. She has developed IoT based Research Projects. Her area of interest is Embedded systems and IoT based designs.

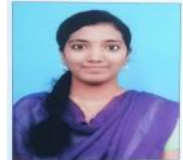

K.Harini, persuing BE (ECE) $3^{\text {rd }}$ year in RMK College of Engineering \& Technology, Chennai. She has developed IoT based Research Projects. Her area of interest is Digital system design and Embedded systems.

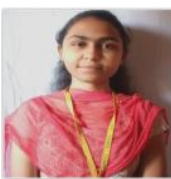

K.Hemalatha, persuing BE (ECE ) $3^{\text {rd }}$ year in RMK College of Engineering \& Technology, Chennai. She has developed IoT based Research Projects. Her area of interest is Digital system design and Communication systems.
Published By:

Blue Eyes Intelligence Engineering and Sciences Publication (BEIESP)

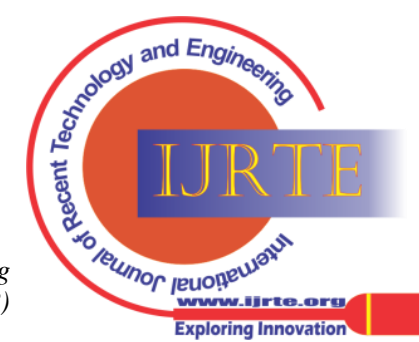

